\title{
Facilely reducing recalcitrance
} of lignocellulosic biomass by a newly developed ethylamine-based deep eutectic solvent for biobutanol fermentation

\author{
Guochao Xu ${ }^{1 \dagger}$, Hao Li ${ }^{1 \dagger}$, Wanru Xing ${ }^{1}$, Lei Gong ${ }^{1}$, Jinjun Dong ${ }^{1}$ and $\mathrm{Ye} \mathrm{Ni}^{1,2^{*}}(\mathbb{0}$
}

\begin{abstract}
Background: Biobutanol is promising and renewable alternative to traditional fossil fuels and could be produced by Clostridium species from lignocellulosic biomass. However, biomass is recalcitrant to be hydrolyzed into fermentable sugars attributed to the densely packed structure by layers of lignin. Development of pretreatment reagents and processes for increasing surface area, removing hemicellulose and lignin, and enhancing the relative content of cellulose is currently an area of great interest. Deep eutectic solvents (DESs), a new class of green solvents, are effective in the pretreatment of lignocellulosic biomass. However, it remains challenging to achieve high titers of total sugars and usually requires combinatorial pretreatment with other reagents. In this study, we aim to develop novel DESs with high application potential in biomass pretreatment and high biocompatibility for biobutanol fermentation.

Results: Several DESs with betaine chloride and ethylamine chloride (EaCl) as hydrogen bond acceptors were synthesized. Among them, EaCl:LAC with lactic acid as hydrogen bond donor displayed the best performance in the pretreatment of corncob. Only by single pretreatment with EaCl:LAC, total sugars as high as $53.5 \mathrm{~g} \mathrm{~L}^{-1}$ could be reached. Consecutive batches for pretreatment of corncob were performed using gradiently decreased cellulase by $5 \mathrm{FPU} \mathrm{g}^{-1}$. At the end of the sixth batch, the concentration and specific yield of total sugars were $58.8 \mathrm{~g} \mathrm{~L}^{-1}$ and $706 \mathrm{~g} \mathrm{~kg}^{-1}$ pretreated corncob, saving a total of 50\% cellulase. Utilizing hydrolysate as carbon source, butanol titer of $10.4 \mathrm{~g} \mathrm{~L}^{-1}$ was achieved with butanol yield of $137 \mathrm{~g} \mathrm{~kg}^{-1}$ pretreated corncob by Clostridium saccharobutylicum DSM13864.
\end{abstract}

Conclusions: Ethylamine and lactic acid-based deep eutectic solvent is promising in pretreatment of corncob with high total sugar concentrations and compatible for biobutanol fermentation. This study provides an efficient pretreatment reagent for facilely reducing recalcitrance of lignocellulosic materials and a promising process for biobutanol fermentation from renewable biomass.

Keywords: Deep eutectic solvent, Lignocellulosic biomass, Ethylamine, Pretreatment, Biobutanol

*Correspondence: yni@jiangnan.edu.cn

${ }^{\dagger}$ Guochao Xu and Hao Li contributed equally to this work

${ }^{1}$ Key Laboratory of Industrial Biotechnology, Ministry of Education,

School of Biotechnology, Jiangnan University, Wuxi 214122, Jiangsu, China

Full list of author information is available at the end of the article

\section{Background}

Biofuels are promising, renewable and natural alternatives to traditional fossil fuels and have gained great interest [1]. Among them, biobutanol possesses great potential due to its high hydrophobicity, high energy density, low corrosiveness and more compatibility in mixing with gasoline $[2,3]$. Moreover, biobutanol could be produced by Clostridium species from lignocellulosic

(c) The Author(s) 2020. This article is licensed under a Creative Commons Attribution 4.0 International License, which permits use, sharing, adaptation, distribution and reproduction in any medium or format, as long as you give appropriate credit to the original author(s) and the source, provide a link to the Creative Commons licence, and indicate if changes were made. The images or other third party material in this article are included in the article's Creative Commons licence, unless indicated otherwise in a credit line to the material. If material is not included in the article's Creative Commons licence and your intended use is not permitted by statutory regulation or exceeds the permitted use, you will need to obtain permission directly from the copyright holder. To view a copy of this licence, visit http://creativeco mmons.org/licenses/by/4.0/. The Creative Commons Public Domain Dedication waiver (http://creativecommons.org/publicdomain/ zero/1.0/) applies to the data made available in this article, unless otherwise stated in a credit line to the data. 
biomass including agricultural waters, forestry residues, grasses and woody materials, which are abundant and renewable resources on the earth. Generally, there are about $10-25 \%$ lignin, $20-30 \%$ hemicellulose, and $40-50 \%$ cellulose in most agricultural lignocellulosic biomass, which can be converted into fermentable sugars, valueadded fine chemicals and materials, etc. [4]. Nevertheless, most of agricultural lignocellulosic resources have been improperly disposed by open field burning. This common practice has led to the emission of pollutants such as $\mathrm{CO}_{2}, \mathrm{CO}, \mathrm{NO}_{\mathrm{X}}, \mathrm{SO}_{2}$, dioxins, etc. [5-7], resulting in air pollution and threatening public health $[8,9]$. According to statistics, more than 800 million tons of agricultural lignocellulosic biomass has been produced annually in China since 2008, and only about half of the biomass was utilized as fertilizer or feed. Among them, corncob is one of the most important lignocellulosic materials with relatively higher contents of cellulose and hemicellulose and lower lignin amount, especially suitable for biofuels production $[10,11]$.

Although lignocellulosic biomass displays great potential in producing renewable energy, it is recalcitrant to be hydrolyzed into fermentable sugars attributed to the densely packed structure by layers of lignin $[12,13]$. Pretreatment of biomass, aiming at increasing surface area, removing hemicellulose and lignin, and enhancing the relative content of cellulose, is required to enhance its accessibility to cellulases for conversion into fermentable sugars. An ideal pretreatment method should be efficient in removal of lignin and hemicellulose, cost-effective and energy-efficient, and highly biocompatible $[4,14]$. There are various pretreatment methods, including alkali, acids, ionic liquids, organic solvents, thermal, pressure, etc. $[15,16]$. Among them, acidic pretreatment methods have been intensively studied, possessing significant advantages of low-cost and high efficiency in destruction of biomass recalcitrance [17]. However, acids are corrosive to equipment and toxic to cellulases and microorganisms. Ionic liquids (ILs), generally consisted of hydrogen bond donor (HBD) and hydrogen bond acceptor (HBA), are promising reagents and have gained tremendous attention due to their low melting temperature, tunable combinations of various cation and anion, easy preparation, low vapor pressure, recyclability and biocompatibility [18]. Various ILs have been developed and applied in biomass pretreatment, such as $[\mathrm{Bmim}][\mathrm{Cl}],[\mathrm{Bmin}]\left[\mathrm{H}_{2} \mathrm{SO}_{4}\right]$ or [Emim] [Cl] [19-21]. However, traditional ILs are expensive and less effective in reducing the recalcitrance, usually requiring other combinatorial methods such as alkaline. Deep eutectic solvents (DESs) are also made up of HBD and HBA, and emerging as a new class of ILs with similar physical and chemical properties.
Most importantly, DESs are advantageous due to their easy preparation, high stability, good biodegradability and biocompatibility [22-24]. Choline chloride $(\mathrm{ChCl})$, a bulk chemical, based deep eutectic solvents was firstly synthesized by Abbott at 2004 [25]. Since then, various ChCl-based DESs have been developed and attempted in the pretreatment of various lignocellulosic biomass such as corn stover, corncob, rice straw, bamboo shell, etc., with high efficiency in removing lignin [3, 26-29]. Endeavor has been committed in optimizing the HBDs including organic or inorganic acids, amino acids, alcohols and sugars. In fact, $\mathrm{ChCl}$-based DESs display similar or ever higher efficiency in reducing the recalcitrance of lignocellulosic biomass than traditional ILs such as $[\mathrm{BMIM}][\mathrm{Cl}]$, attributing to the similar mechanism of providing or receiving $\mathrm{H}$-bond or localizing charges on the chemical bonds of biomass through electrostatic forces of the ionic pairs [30]. However, high titers $\left(>50 \mathrm{~g} \mathrm{~L}^{-1}\right)$ of fermentable sugars are hard to be achieved by single pretreatment with $\mathrm{ChCl}$ based DESs. Generally, condensation under vacuum or combinatorial pretreatment methods such as $\mathrm{NaOH}$, $\mathrm{Na}_{2} \mathrm{CO}_{3}$ or microwave radiation should be introduced, inevitably complicating the process and resulting in low solid yield and high consumption of water for removing residual alkaline. As a result, the utilization of lignocellulosic biomass with high yields and titers of total sugars remains challenging [31]. Development of novel DESs with enhanced properties in pretreating biomass is of significant interest for biofuels production from abundant and renewable biomass.

In principle, ammonium, phosphonium, or sulfonium cation in halide form could be used as HBAs, while amides, carboxylic and alcohols could be used as HBDs [32]. Development of novel DESs can be achieved by rational complexation of HBDs and HBAs to form eutectic liquids. However, the procedures are empirical and labor-intensive, and most combinations are unsuccessful in forming homogeneous and clear liquids. Density functional theory (DFT) calculations play an important role in elucidating the mechanism of chemical or enzymatic reactions and also predicting the reactivity [33, 34]. Here, DFT calculation was adopted to evaluate the feasibility in synthesis of novel DESs. Cheap and bulk chemicals including $\mathrm{ChCl}$, betaine chloride $(\mathrm{BaCl})$ and ethylamine chloride $(\mathrm{EaCl})$ were investigated as HBAs (Scheme 1) for developing efficient DESs. Newly synthesized DESs were evaluated for removing of lignin and hemicellulose, as well as their effects on increasing cellulose accessibility of biomass. Corncob hydrolysates were also examined in biobutanol fermentation by Clostridium saccharobutylicum DSM13864. 

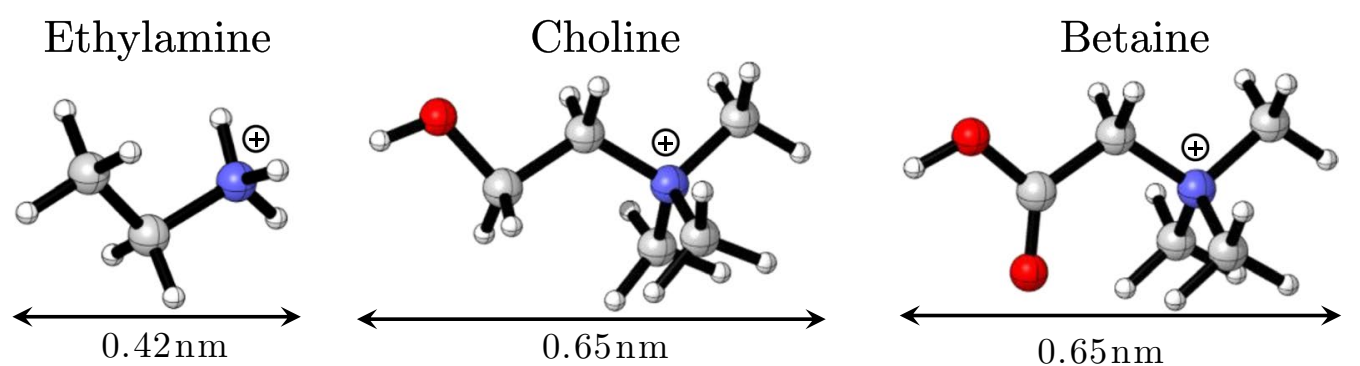

Scheme 1. Structures of ethylamine chloride, choline chloride and betaine chloride used as hydrogen bond acceptors. Atoms are carbon (gray), nitrogen (blue), oxygen (red), and hydrogen (white). $\mathrm{Cl}^{-}$ion is not shown

\section{Results and discussion Synthesis of DESs}

Betaine chloride $(\mathrm{BaCl})$ and ethylamine chloride $(\mathrm{EaCl})$ possess similar structure as $\mathrm{ChCl}$, they were explored as HBA in the synthesis of DESs. As shown in Scheme 1, $\mathrm{EaCl}$ is smaller than $\mathrm{ChCl}$, while $\mathrm{BaCl}$ is similar to $\mathrm{ChCl}$. All of them contain quaternary nitrogen cation, which is favorable to DES formation. There is a free hydroxy group in $\mathrm{ChCl}$, a carboxyl group in $\mathrm{BaCl}$ and a free aliphatic terminal in $\mathrm{EaCl}$. Lactic acid (LAC), ethyl glycol (EG), glycerol (GLY) and urea (UR), which have been commonly used and proved to be effective in forming DESs with $\mathrm{ChCl}$, were introduced as HBDs. Generally, DESs were empirically synthesized by combination of various kinds and ratios of HBD and HBA. However, most of the combinations were hard to be synthesized. Considering these unpredictable combination patterns, both experimental synthesis employing methods for ChCl-based DESs and DFT calculations with different functions were performed to explore the feasibility of rational design of DESs.

For $\mathrm{ChCl}$ and $\mathrm{EaCl}$-based DESs, all of the four combinations, $\mathrm{ChCl}: \mathrm{LAC}, \mathrm{ChCl}: \mathrm{EG}, \mathrm{ChCl}$ :GLY and $\mathrm{ChCl}: \mathrm{UR}$, $\mathrm{EaCl}: \mathrm{LAC}, \mathrm{EaCl}: \mathrm{EG}, \mathrm{EaCl}: \mathrm{GLY}$ and $\mathrm{EaCl}: \mathrm{UR}$, respectively, were successfully obtained. However, with regard to $\mathrm{BaCl}$ as HBA, only $\mathrm{BaCl}: \mathrm{EG}$ and $\mathrm{BaCl}$ :GLY could be facilely synthesized in clear and homogenous liquid. It should be mentioned that further optimization of reaction conditions such as ratios of HBD to HBA and temperature might also produce $\mathrm{BaCl}: \mathrm{LAC}$ and $\mathrm{BaCl}: \mathrm{UR}$. Furthermore, $\Delta G_{\mathrm{rxn}}$ of the reaction $\left(\Delta G_{\mathrm{rxn}}=G_{\mathrm{DES}}-G\right.$ $\mathrm{HBA}-n \times G_{\mathrm{HBD}}$ ) was calculated employing three mostly common used DFT including B3LYP, M062X and $\omega B 97 X$ and basis set of $6-311+G^{* * *}$. Negative values of $\Delta G_{\mathrm{rxn}}$ can be used to indicate the thermodynamical feasibility. Previously, B3LYP and M062X have been used in the simulation of ChCl-based DESs [35-38]. In Table $1, \Delta G_{\text {rxn }}$ values of easily obtained DESs were lower than 0 , according to the $\Delta G_{\mathrm{rxn}}$ results of B3LYP
Table 1 Deep eutectic solvents synthesized in this study

\begin{tabular}{|c|c|c|c|c|}
\hline DES & $\begin{array}{l}\text { Ratio } \\
\text { of HBA } \\
\text { to HBD }\end{array}$ & $\begin{array}{l}\Delta G_{\mathrm{rrn}}^{\mathrm{B} 3 \mathrm{LYP}} \\
\left(\mathrm{kcal} \mathrm{mol}^{-1}\right)\end{array}$ & $\begin{array}{l}\Delta G_{\mathrm{rxn}}^{\mathrm{M} 062 \mathrm{X}} \\
\left(\mathrm{kcal} \mathrm{mol}^{-1}\right)\end{array}$ & $\begin{array}{l}\Delta G_{\mathrm{rxn}}^{\omega \mathrm{Bg}} \\
\left(\mathrm{kcal}^{\mathrm{mol}} \mathrm{mol}^{-1}\right)\end{array}$ \\
\hline ChCl:UR & $1: 2$ & -2.54 & -6.39 & -6.50 \\
\hline ChCl:EG & $1: 2$ & -2.84 & -7.15 & -6.55 \\
\hline ChCl:GLY & $1: 2$ & -2.27 & -2.86 & -2.58 \\
\hline ChCl:LAC & $1: 1$ & -8.96 & -10.3 & -9.95 \\
\hline BaCl:UR & $1: 2$ & 3.59 & -10.8 & -0.54 \\
\hline $\mathrm{BaCl}: \mathrm{EG}$ & $1: 2$ & -1.42 & -11.2 & -7.15 \\
\hline $\mathrm{BaCl}: \mathrm{GLY}$ & $1: 2$ & -1.21 & -9.88 & -1.73 \\
\hline $\mathrm{BaCl}: \mathrm{LAC}$ & $1: 1$ & 1.03 & -4.92 & -3.23 \\
\hline EaCl:UR & $1: 2$ & -2.25 & -4.55 & -3.80 \\
\hline EaCl:EG & $1: 2$ & -1.62 & -4.21 & -1.73 \\
\hline EaCl:GLY & $1: 2$ & -2.38 & -4.19 & -3.31 \\
\hline EaCl:LAC & 1:1 & -4.67 & -7.94 & -8.23 \\
\hline
\end{tabular}

$\mathrm{ChCl}$ choline chloride, $\mathrm{BaCl}$ betaine chloride, $\mathrm{EaCl}$ ethylamine chloride, UR urea, $E G$ ethylene glycol, $G L Y$ glycine, $L A C$ lactic acid

$\left(\Delta G_{\mathrm{rxn}}^{\mathrm{B} 3 \mathrm{LYP}}\right)$. Especially, the $\Delta G_{\mathrm{rxn}}^{\mathrm{B} 3 \mathrm{LY}}$ values of $\mathrm{ChCl}$ :LAC and EaCl:LAC were the lowest. With regard to $\mathrm{BaCl}: \mathrm{LAC}$ and $\mathrm{BaCl}: \mathrm{UR}$, the $\Delta G_{\mathrm{rxn}}^{\mathrm{B} L Y P}$ values were 3.59 and $1.03 \mathrm{kcal} \mathrm{mol}^{-1}$, respectively. For the results using M062X, there is no definite patterns. For example, the $\Delta G_{\mathrm{rxn}}^{\mathrm{M} 062 \mathrm{X}}$ value of $\mathrm{BaCl}: \mathrm{UR}$ was $-10.8 \mathrm{kcal} \mathrm{mol}^{-1}$, ranking the lowest, whereas, $\Delta G_{\mathrm{rxn}}^{\mathrm{B} 3 \mathrm{LYP}}$ of BaCl:UR was the highest. All the $\Delta G_{\mathrm{rxn}}^{\omega \mathrm{B} 97 \times D}$ values were negative, which were hard to be correlated with the reactivity. As a result, calculation method of $\mathrm{B} 3 \mathrm{LYP} / 6-311+\mathrm{G}^{* * *}$ is more favorable in predicting the potential of DES synthesis, and might be used to elucidate the reactivity and mechanism of DES mediated systems in pretreatment of lignocellulosic biomass.

The optimized geometries of EaCl:LAC, ChCl:LAC and $\mathrm{BaCl}$ :LAC were obtained from DFT calculations. Distance and interactions among HBD and HBA were also analyzed. Three potential hydrogen bonds could formed between $\mathrm{EaCl}$ and $\mathrm{LAC}$, which are favorable for 

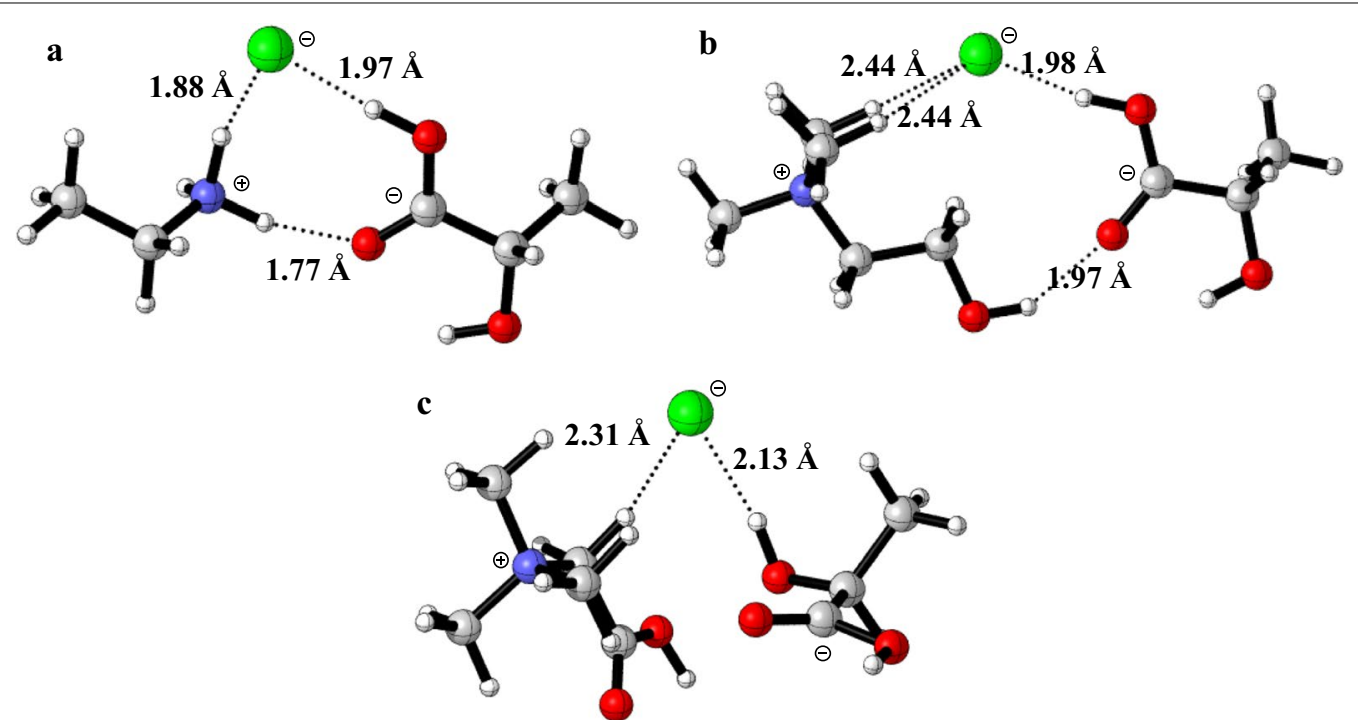

Fig. 1 Chemical structures of EaCl:LAC (a), ChCl:LAC (b) and BaCl:LAC obtained from geometry optimization

the formation of EaCl:LAC (Fig. 1a). In addition, due to the small size of $\mathrm{EaCl}$, the strong electrostatic interaction between nitrogen cation of ethylamine and carboxy group of lactic acid could also contribute to the stabilization of EaCl:LAC. In ChCl:LAC, two hydrogen bonds could be formed between $\mathrm{ChCl}$ and LAC (Fig. 1b). However, the distance from nitrogen cation and carboxyl group is too large to form stable interaction. With regard to $\mathrm{BaCl}$ :LAC, few interactions were found between $\mathrm{BaCl}$ and LAC (Fig. 1c), which might account for the high $\Delta G_{\mathrm{rxn}}$ value and also the difficulties in preparation of $\mathrm{BaCl}: \mathrm{LAC}$. It is well known that electrostatic forces of the ions in ILs or DESs could provide or receive $\mathrm{H}$-bond or localize charges on the chemical bonds of the matrix of lignocellulosic biomass. As a result, EaCl:LAC is presumably to display high efficacy in pretreatment of lignocellulosic biomass.

\section{Evaluation of EaCl:LAC in the pretreatment of lignocellulosic biomass}

The effect of newly synthesized DESs in pretreatment was investigated with rice straw. ChCl:LAC was regarded as a positive control since it had been applied in pretreatment of rice straw and lignin extraction [39, 40]. Total sugars including glucose, xylose and arabinose were determined. As illustrated in Fig. 2a, EaCl:LAC exhibited the highest efficacy, with total sugars concentration of $32.1 \mathrm{~g} \mathrm{~L}^{-1}$. The concentration of total sugars obtained from $\mathrm{ChCl}$ :LAC is $17.4 \mathrm{~g} \mathrm{~L}^{-1}$, ranking the second. The good performance of $\mathrm{EaCl}: \mathrm{LAC}$ and $\mathrm{ChCl}$ :LAC proves the effectiveness of DESs with lactic acid as HBD. About $17.2 \mathrm{~g} \mathrm{~L}^{-1}$ total sugars were achieved for rice straw pretreated by $\mathrm{BaCl}$ GLY, which was similar to that of ChCl:LAC. To further prove the effectiveness of $\mathrm{EaCl}: \mathrm{LAC}, \mathrm{EaCl}$ and LAC were separately applied in the pretreatment of RS. The total sugars concentrations of $\mathrm{EaCl}$ and $\mathrm{LAC}$ were 9.32 and $13.0 \mathrm{~g} \mathrm{~L}^{-1}$, accounting for $29.0 \%$ and $40.6 \%$ of that of $\mathrm{EaCl}: \mathrm{LAC}$, respectively, indicating the synergistic effect $\mathrm{EaCl}$ and LAC. Moreover, the remarkable performance of $\mathrm{EaCl}: \mathrm{LAC}$ in pretreatment of biomass is in consistence with its structural property.

To further explore the potential of this newly synthesized $\mathrm{EaCl}$ :LAC, pretreatment of various lignocellulosic biomass including rice husk, pod, wheat straw, corncob and bagasse were performed. As illustrated in Fig. 2b, EaCl:LAC was effective in the pretreatment of various lignocellulosic biomass except for rice husk. The highest sugar concentration of $53.5 \mathrm{~g} \mathrm{~L}^{-1}$ was obtained with corncob, including $48.5 \mathrm{~g} \mathrm{~L}^{-1}$ glucose, $2.48 \mathrm{~g} \mathrm{~L}^{-1}$ xylose and $2.60 \mathrm{~g} \mathrm{~L}^{-1}$ arabinose. The sugar concentration of corncob was $38.1-489 \%$ higher than $38.8 \mathrm{~g} \mathrm{~L}^{-1}$ of bagasse, $34.8 \mathrm{~g} \mathrm{~L}^{-1}$ of rice straw, $29.2 \mathrm{~g} \mathrm{~L}^{-1}$ of wheat straw, $22.3 \mathrm{~g} \mathrm{~L}^{-1}$ of pod and $9.0 \mathrm{~g} \mathrm{~L}^{-1}$ of rice husk, respectively. Furthermore, the total sugars concentration of corncob pretreated by $\mathrm{EaCl}: \mathrm{LAC}$ was even higher than those of corn stover and RS which were combinatorially pretreated by $[\mathrm{Bmim}][\mathrm{Cl}]$ and $\mathrm{NaOH}$ or $\mathrm{ChCl}: \mathrm{FA}: \mathrm{AA}$ and $\mathrm{Na}_{2} \mathrm{CO}_{3}[3,41]$. This newly synthesized ethylamine-based $\mathrm{DES}, \mathrm{EaCl}$ :LAC, is promising in reducing the recalcitrance of various lignocellulosic biomass.

To further evaluate the effects of $\mathrm{EaCl}: \mathrm{LAC}$ in reducing the recalcitrance of biomass, component analysis was conducted. Contents of cellulose, hemicellulose and lignin were determined and shown in Table 2. For raw 

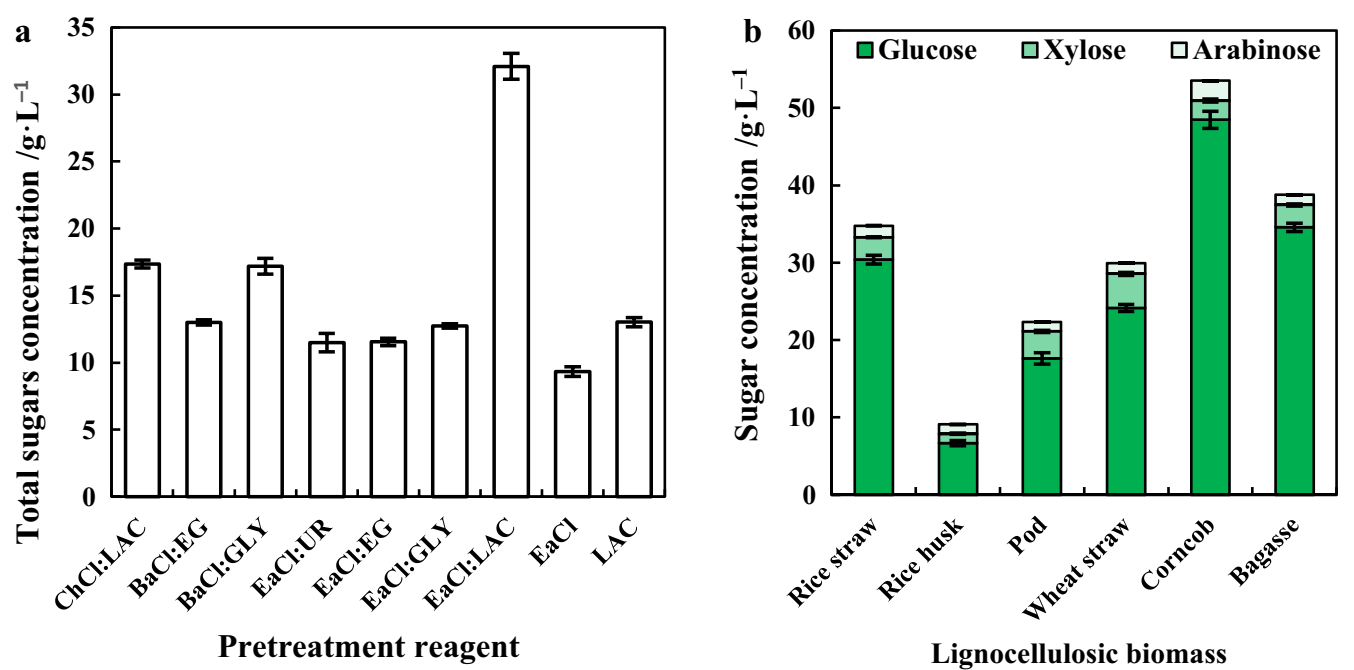

Fig. 2 Evaluation of newly synthesized DESs in the pretreatment of various lignocellulosic biomass. a Pretreatment of rice straw by various DESs. $\mathbf{b}$ Pretreatment of various lignocellulosic biomass by EaCl:LAC. $\square$, glucose; $\square$ ):xylose, $(\square)$ arabinose

biomass, the cellulose content of corncob was $30.0 \%$, which was higher than that of pod $(21.8 \%)$ whereas much lower than $38.1 \%$ of wheat straw, $35.0 \%$ of rice husk, $32.0 \%$ bagasse and $31.7 \%$ of rice straw. Remarkably, the cellulose content of corncob was increased to $70 \%$ after pretreatment with EaCl:LAC. In fact, cellulose contents of all other tested biomass were increased to some extent (11-34\%), indicating the effectiveness of $\mathrm{EaCl}$ LAC in reducing recalcitrance of biomass. The cellulose yield of corncob was as high as $98.0 \%$, much higher than other biomass. The hemicellulose contents of corncob, rice straw, pod, wheat straw, bagasse and rice husk were $14.6 \%, 10.0 \%, 10.9 \%, 8.4 \%, 11.6 \%$ and $6.7 \%$, respectively. After EaCl:LAC pretreatment, the hemicellulose removal of $87.9 \%, 81.1 \%, 75.3 \%, 69.9 \%, 83.1 \%$ and $62.7 \%$ were achieved for corncob, rice straw, pod, wheat straw, bagasse and rice husk. With regard to lignin including acid-soluble and acid-insoluble, their content in corncob was $26.5 \%$, while in rice straw, pod, wheat straw and rice husk were higher than $30 \%$. The lignin removal of corncob and wheat straw was $71.5 \%$ and $67.0 \%$, respectively, much higher than $61.3 \%, 42.7 \%, 57.2 \%$ and $62.7 \%$ of rice straw, pod, bagasse and rice husk. The solid recovery rate of all the tested biomass fell into a range of $40-58 \%$. It should be noted that other components including pigments, proteins, fatty acids, etc., accounted for $9.7-44.5 \%$ of raw biomass (Table 2). Most of them could also be efficiently removed by EaCl:LAC pretreatment (Table 2). The results suggest that EaCl:LAC could effectively reduce the stubborn resistance of lignocellulose and lignin in corncob and enhance the cellulose accessibility to cellulase. The excellent performance of EaCl:LAC in lignin removal is consistent with the high potential of DES in the extraction of lignin and metals [32]. In comparison with other DESs in the pretreatment of corncob, $\mathrm{EaCl}: \mathrm{LAC}$ displayed higher efficiency in removing both hemicellulose and lignin, which is usually difficult to be achieve by choline chloride or betaine-based DESs (Additional file 1) [42]. Generally, combinatorial pretreatment method using alkaline or oxidant should be introduced to achieve higher glucose yield. As a result, the newly developed EaCl:LAC is an efficient pretreatment reagent for lignocellulosic biomass.

\section{Physical characterization of corncob pretreated by EaCl:LAC}

In corncob, lignin and hemicellulose form a tight network structure wrapping around the outer layer of cellulose, which seriously hinders the accessibility of cellulose by cellulase [13]. SEM analysis was implemented to monitor the surface structure of untreated and pretreated corncobs (Additional file 2). In untreated corncob, a smooth and compact surface with strong rigid structure was observed. However, an entirely different landscape was detected in the pretreated corncob. The surface of pretreated corncob became loose and rough with obvious fracture delamination, revealing destroyed lignin and hemicellulose around cellulose, which was favorable for improved cellulose accessibility in corncob. Moreover, the observed changes in corncob surface are consistent with the high lignin and hemicellulose removal after $\mathrm{EaCl}:$ LAC pretreatment.

Furthermore, XRD assay was conducted to explore changes of the crystallinity index (CrI) of untreated and 


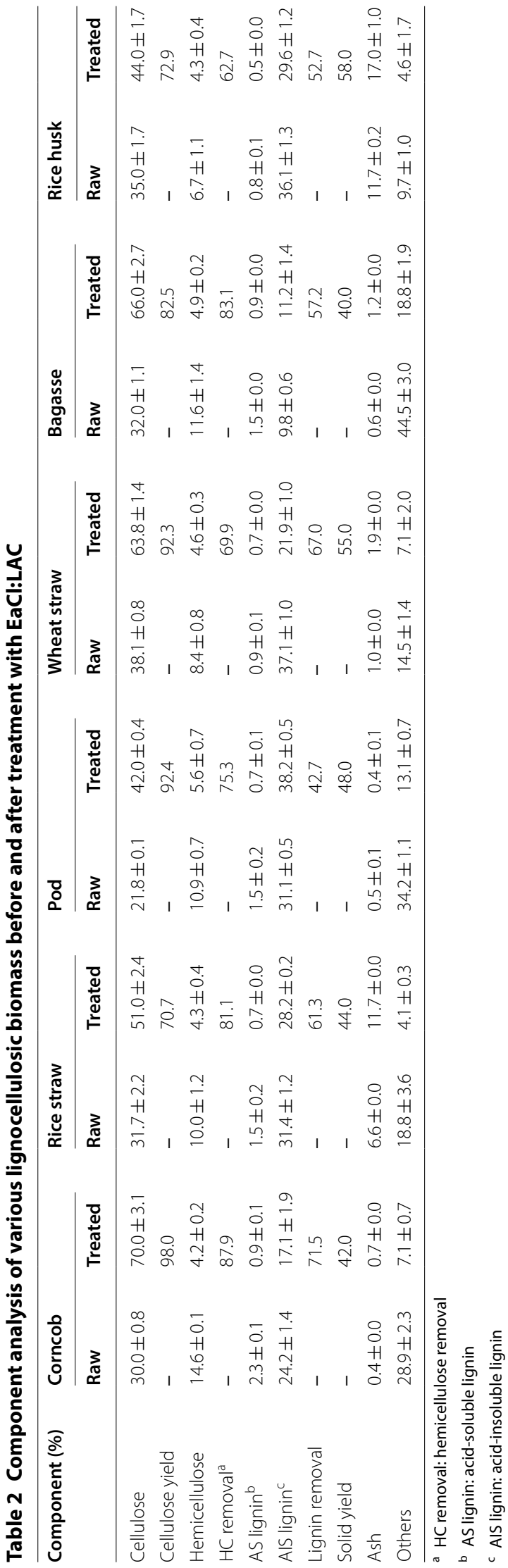

pretreated corncobs. According to the overlapped XRD spectrum (Additional file 3), no new peak appeared in the pretreated corncob, indicating no structural change after pretreatment. The diffraction peaks at $16^{\circ}$ and $21^{\circ}$ represent the typical crystalline structures of cellulose I, and could be used to calculate CrI [11]. The CrI value could be regarded as an indicator for the exposure and accessibility of cellulose. Above two characteristic absorption peaks of pretreated corncob were much higher than those of raw corncob, largely due to the increased cellulose content after removal of lignin and hemicellulose. The CrI values of raw and pretreated corncob were $31.0 \%$ and $42.8 \%$, respectively. The increased CrI value of pretreated corncob agrees with the increased cellulose content (Table 2), and indicates the successful removal of certain stubborn components wrapped around the cellulose. It is favorable for increasing the accessibility of cellulase to cellulose in lignocellulosic biomass [43].

FTIR spectrum of untreated and pretreated corncobs was obtained (Additional file 4). The absorption peaks at 830 and $1166 \mathrm{~cm}^{-1}$ refer to the vibration of $\mathrm{C}-\mathrm{C}$ bond in lignin, indicating the lignin in corncob is SGH lignin (syringyl-guaiacyl-p-hydroxyphenyl) [44]. In comparison with untreated corncob, the characteristic absorption peaks of lignin in pretreated corncob were significantly reduced, revealing that a large amount of lignin was removed. The absorption peak at $1638 \mathrm{~cm}^{-1}$ is attributed to the stretching vibration of $\gamma$-lactone, and the decrease value means that the lignin was largely removed after pretreatment $[28,45]$. The increased absorption peak at $895 \mathrm{~cm}^{-1}$, relating to $\beta$-glycosidic bond in cellulose, indicates the removal of hemicellulose and exposure of more cellulose. Furthermore, the absorption peak at $1383 \mathrm{~cm}^{-1}$ is caused by the stretching vibration of $\mathrm{C}-\mathrm{H}$ bond in cellulose, and the increased value shows that the amorphous cellulose was removed after EaCl:LAC pretreatment. The absorption peak at $1736 \mathrm{~cm}^{-1}$ represents the vibration of carboxyl group in hemicellulose, and the decreased adsorption peak of pretreated corncob reveals the removal of hemicellulose in comparison with raw corncob [44]. In summary, the FTIR result agrees with the composition analysis. After pretreatment with $\mathrm{EaCl}$ :LAC, a large amount of lignin and hemicellulose in corncob were removed, and the relative content of cellulose was significantly increased to $70.0 \%$, resulting in enhanced cellulose accessibility.

\section{Development of fed-batch pretreatment process}

To establish an efficient and economic corncob pretreatment process, various factors were optimized. Firstly, conditions including temperature, incubation time and solid-liquid ratios were systematically investigated, and the resultant corncobs pretreated by $\mathrm{EaCl}: \mathrm{LAC}$ were 
subjected to enzymatic hydrolysis for determination of total sugars (Additional file 5). At $90{ }^{\circ} \mathrm{C}$ and $110{ }^{\circ} \mathrm{C}$, elongated pretreatment time from 0.5 to $3.0 \mathrm{~h}$ resulted in higher total sugars. However, when the temperature increased to $130{ }^{\circ} \mathrm{C}$ and $150{ }^{\circ} \mathrm{C}$, different profiles were observed. At over $130{ }^{\circ} \mathrm{C}$, longer incubation time led to decreased total sugars, which might be attributed to the destruction of cellulose structure. As a result, either high temperature for short time or low temperature for long time is beneficial to the performance of EaCl:LAC. Under the optimum pretreatment conditions of $150{ }^{\circ} \mathrm{C}$ for $0.5 \mathrm{~h}$ and solid-liquid ratio of 1:15, the highest total sugars concentration of about $55.6 \mathrm{~g} \mathrm{~L}^{-1}$ were obtained from the pretreated corncob (Additional file 5).

Furthermore, factors including cellulase dosage, hydrolysis time, solid to liquid ratio and supplementation of Tween80, which might influence the enzymatic hydrolysis process, were investigated. Different amounts of cellulase, ranging from 10 to $70 \mathrm{FPU} \mathrm{g}^{-1}$ pretreated corncob, were loaded, and the released total sugars were monitored as illustrated in Fig. 3a. Along with the increase of hydrolysis time, the total sugars elevated rapidly during the initial $24 \mathrm{~h}$, and then slowly increased until $72 \mathrm{~h}$. Although longer hydrolysis time could lead to higher concentrations of total sugars, it also results in compromised space-time yield. At $50 \mathrm{FPU} \mathrm{g}^{-1}$ cellulase, total sugars of $57.0 \mathrm{~g} \mathrm{~L}^{-1}$ was obtained at $24 \mathrm{~h}$, merely $4.5 \mathrm{~g} \mathrm{~L}^{-1}$ lower than that of $70 \mathrm{FPU} \mathrm{g}{ }^{-1}$ cellulase. Considering the relative lower loading of cellulase and higher efficiency, hydrolysis with $50 \mathrm{FPU} \mathrm{g}^{-1}$ cellulase for $24 \mathrm{~h}$ was selected as the suitable condition. Influence of solid to liquid ratios at 1:8, 1:10, 1:12 and 1:15 on releasing of total sugars were also investigated at $50 \mathrm{FPU} \mathrm{g}^{-1}$ cellulase (Fig. 3b). Increased liquid ratios represent lower addition of biomass. Along with the increase of solid to liquid ratios, the total sugars decreased from 64 to $44 \mathrm{~g} \mathrm{~L}^{-1}$ after $24 \mathrm{~h}$ of hydrolysis. The total sugar yield per pretreated corncob increased from 513 to $661 \mathrm{~g} \mathrm{~kg}^{-1}$. Although enhanced total sugar yield could be achieved at a relatively high liquid ratio at the expense of cellulase, however, lower titer of total sugars could be resulted, which is disadvantageous for biobutanol fermentation since extra energy-consuming concentration step is required to increase the sugar concentration. In the view of better mass transferring and relatively higher total sugars, solid to liquid ratio of 1:12 is considered as optimum, at which the total sugars of $50 \mathrm{~g} \mathrm{~L}^{-1}$ could be achieved after $24 \mathrm{~h}$ of hydrolysis.

Although most of the lignin and hemicellulose could be removed from corncob after $\mathrm{EaCl}$ :LAC pretreatment, residual lignin could competitively adsorb free cellulase, which might result in losing of cellulase and impairing hydrolysis efficiency. Supplementation of bovine serum albumin (BSA) or Tween 80 has been proved to be effective solutions for reducing inefficient adsorption of cellulase on lignin and deactivation of absorbed cellulase by enzyme-substrate interaction [46, 47]. Herein, addition of Tween 80 was also attempted (Fig. 3c). In comparison with the control (without Tween80), supplementation of $0.1-1.0 \%(\mathrm{v} / \mathrm{v})$ of Tween 80 resulted in increased total sugars. At $1.0 \%$ Tween 80 , total sugars concentration of as high as $55.1 \mathrm{~g} \mathrm{~L}^{-1}$ was attained, $10.2 \%$ higher than $50.0 \mathrm{~g} \mathrm{~L}^{-1}$ of control. Excessive addition of Tween80 could however complicate the compositions and affect the biocompatibility of hydrolysates in biobutanol fermentation. At $0.5 \%$ Tween 80 , the total sugar reached $53.8 \mathrm{~g} \mathrm{~L}^{-1}$, which was adequate for butanol fermentation [38]. As a result, addition of $0.5 \%$ Tween 80 is selected for the hydrolysis of pretreated corncob into fermentable sugars.

To further reduce the enzyme loading, cellulases absorbed on residual corncobs were recycled and reused in the consecutive batches. Herein, two processes with and without addition of $0.5 \%$ Tween 80 were evaluated. At the end of each batch, the residual solids which might absorb cellulases as previous reported [3], were collected and reloaded into the next batch. The loadings of cellulase were decreased by $5 \mathrm{FPU} \mathrm{g}^{-1}$ for the following batches. The absorbed cellulases were recycled for five times, and sugars including glucose, xylose and arabinose were determined and illustrated in Fig. 4. The total sugars increased rapidly within the initial $6 \mathrm{~h}$, and the addition of cellulase attached to corncob did not result in a decrease in enzymatic efficiency since it could lead to compromised mass transfer compared with the first batch (Cycle I). In the process with Tween80 (Fig. 4b), total sugars concentration of Cycle I was $52.9 \mathrm{~g} \mathrm{~L}^{-1}$, while it was $49.5 \mathrm{~g} \mathrm{~L}^{-1}$ in control (without Tween80) (Fig. 4a). Addition of Tween 80 was favorable for the enzymatic hydrolysis, exhibiting 7-14\% increase in total sugars at each batch. In the sixth batch (Cycle IV), only $25 \mathrm{FPU} \mathrm{g}^{-1}$ of fresh cellulase was supplemented. The total sugars reached $58.8 \mathrm{~g} \mathrm{~L}^{-1}$ and $54.9 \mathrm{~g} \mathrm{~L}^{-1}$ for processes with and without Tween80, respectively, which were 706 and $659 \mathrm{~g} \mathrm{~kg}^{-1}$ corncob pretreated by EaCl:LAC. The total sugars increased by about $11 \%$ than that of Cycle I. It is presumed that Tween 80 might reduce the inactivation of cellulase caused by interaction between cellulase and substrate. Thus, the cellulases adsorbed on corncob displayed stable and even improved enzymatic activity in the next cycle, which is consistent with previous study [47]. The total sugars concentrations of each batch were enough as carbon source for the butanol fermentation with C. saccharobutylicum. It should be noted that about $50 \%$ of cellulases could be saved through this newly developed recycling process. 

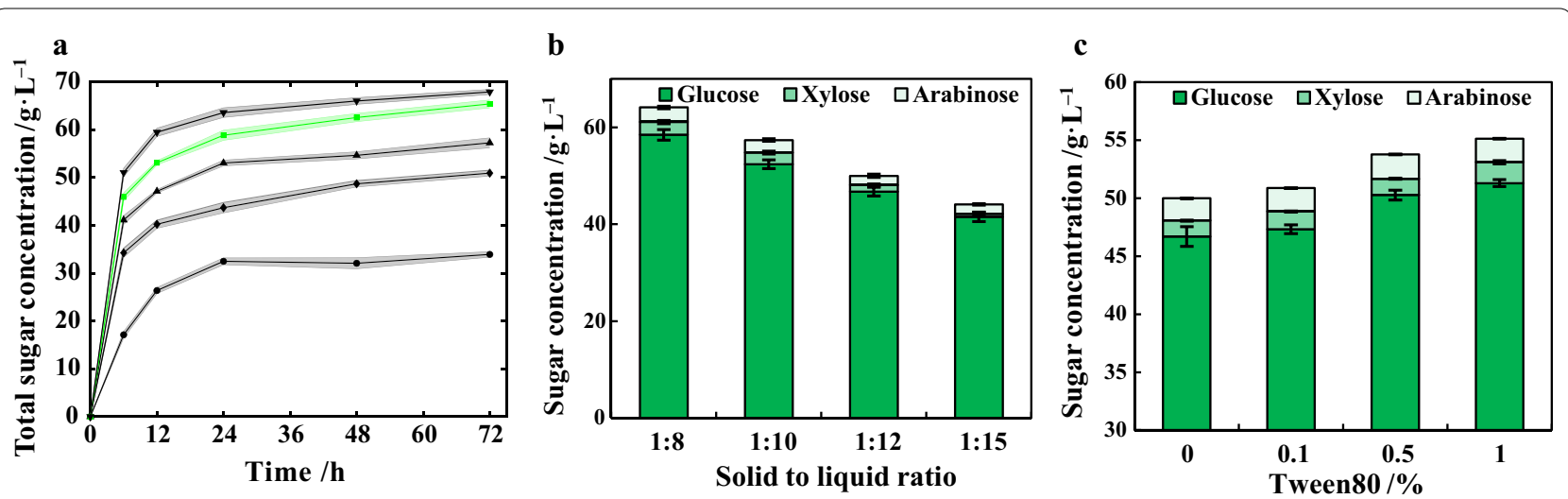

Fig. 3 Optimization of enzymatic hydrolysis conditions. a Cellulase loading and hydrolysis time, ( $): 70 \mathrm{FPU} \mathrm{g}^{-1} ;(\square): 50 \mathrm{FPU} \mathrm{g} \mathrm{g}^{-1},(\mathbf{(}) 40 \mathrm{FPU} \mathrm{g}^{-1}$, $(\checkmark) 30 \mathrm{FPU} \mathrm{g}^{-1},(\mathbf{)}) 10 \mathrm{FPU} \mathrm{g}^{-1}$, shadow refers to standard deviation. b Solid-liquid ratio, $(\square)$ : glucose; $(\square)$ : xylose, $(\square)$ : arabinose. c Tween80, ( $\square$ ): glucose; $\square$ : xylose, $(\square)$ : arabinose. All pretreatment was performed in triplicate

\section{Biobutanol fermentation with corncob hydrolysates by $C$. saccharobutylicum DSM13864}

Application of hydrolysates from EaCl:LAC-pretreated corncob was evaluated in biobutanol fermentation. $C$. saccharobutylicum DSM13864 could utilize pentoses, such as xylose, as carbon sources and is regarded as one of the most promising bacteria for biobutanol fermentation. Hydrolysates of the sixth batch were collected and designated as Cycle $\mathrm{VI}_{\text {Tween80 }}$ and Cycle VI for with and without Tween 80 addition, respectively. The total sugars concentrations of Cycle $\mathrm{VI}_{\mathrm{Tweeen} 80}$ and Cycle VI were determined to be $58.8 \mathrm{~g} \mathrm{~L}^{-1}$ and $54.9 \mathrm{~g} \mathrm{~L}^{-1}$. Control experiments were also carried out with glucose as carbon source instead of hydrolysates. The glucose concentrations of the control groups were kept at the same level with the total sugars of the hydrolysates from Cycle $\mathrm{VI}_{\text {Tween80 }}$ and Cycle VI. Consumption of reducing sugars and production of acetone, butanol and ethanol (ABE) were monitored and illustrated in Fig. 5 and Table 3. During the initial $48 \mathrm{~h}, C$. saccharobutylicum grew quickly with high sugar consumption and $\mathrm{ABE}$ production rates. After $48 \mathrm{~h}, \mathrm{ABE}$ production decreased, along with a slower sugar consumption rate. After $72 \mathrm{~h}$, butanol titers of 10.2 and $10.4 \mathrm{~g} \mathrm{~L}^{-1}$ were reached for Cycle VI (Fig. 5a) and Cycle VI $\mathrm{T}_{\text {Tween80 }}$ (Fig. 5c), respectively, slightly lower than the corresponding glucose controls of 11.2 (Fig. 5b) and $11.4 \mathrm{~g} \mathrm{~L}^{-1}$ (Fig. 5d). Although the concentrations of total sugars in hydrolysates are at same level with glucose controls, they are mixture of arabinose, xylose and glucose. The lower ABE titers of hydrolysates might be attributed to the lower glucose concentrations and the complicated metabolite fluxes of hydrolysates. It should be noted that the butanol yield and productivity of Cycle $\mathrm{VI}_{\text {Tween80 }}$ and Cycle VI hydrolysates were $194 \mathrm{~g} \mathrm{~kg}_{\text {sugar }}^{-1 \text { total }}$ and $0.15 \mathrm{~g} \mathrm{~L}^{-1} \mathrm{~h}^{-1}$, and $206 \mathrm{~g} \mathrm{~kg}_{\text {sugar }}^{-1 \text { total }}$, and $0.14 \mathrm{~g} \mathrm{~L}^{-1} \mathrm{~h}^{-1}$, respectively, which are at similar level with those of glucose controls (Table 3). The specific yields of butanol of Cycle $\mathrm{VI}_{\text {Tween80 }}$ and Cycle VI per pretreated corncob were 137 and $136 \mathrm{~g} \mathrm{~kg}^{-1}$. With regard to total solvents of $\mathrm{ABE}$, the titers of Cycle $\mathrm{VI}_{\text {Tween80 }}$ and Cycle VI were 15.8 and $15.6 \mathrm{~g} \mathrm{~L}^{-1}$, with calculated yields per total sugars of 295 and $315 \mathrm{~g} \mathrm{~kg}_{\text {sugar }}^{-1 \text { total }}$, and calculated yields per pretreated corncob of 208 and $207 \mathrm{~g} \mathrm{~kg}^{-1}$, respectively. As a result, corncob hydrolysates from Cycle VI could be efficiently utilized by $C$. saccharobutylicum as carbon source for biobutanol fermentation. Moreover, the corncob hydrolysates did not display obvious inhibitory effect on the growth and biobutanol production of C. saccharobutylicum.

This study provides a simple and biocompatible process for the facile conversion of corncob into biobutanol. Compared with other established processes, EaCl:LAC is a low-price, environmental friendly and biocompatible reagent. The specific ABE yields per pretreated and raw biomass of this process were calculated to be 208 and $87.4 \mathrm{~g} \mathrm{~kg}^{-1}$, second only to that of corncob pretreated by $0.5 \mathrm{M} \mathrm{NaOH}$ [48]. In view of its low price and high biocompatibility, EaCl:LAC is more efficient and promising than traditional ionic liquids such as $[\mathrm{Bmim}][\mathrm{Cl}]$, and DESs such as ChCl:FA and ChCl:FA:AA. There is no need to add other reagents which are commonly used in combinatorial pretreatments, such as $\mathrm{NaOH}$ or $\mathrm{Na}_{2} \mathrm{CO}_{3}[3$, 41]. Moreover, EaCl:LAC could also be facilely recycled by filtration. The hydrolysates with high titers of reducing sugars could presumably be applied in the biosynthesis of other biofuels, amino acids and high-valued natural products. Consequently, this study provides a promising reagent for significantly reducing the recalcitrance of lignocellulosic biomass, and an economic cellulase recycling process for biobutanol production. 


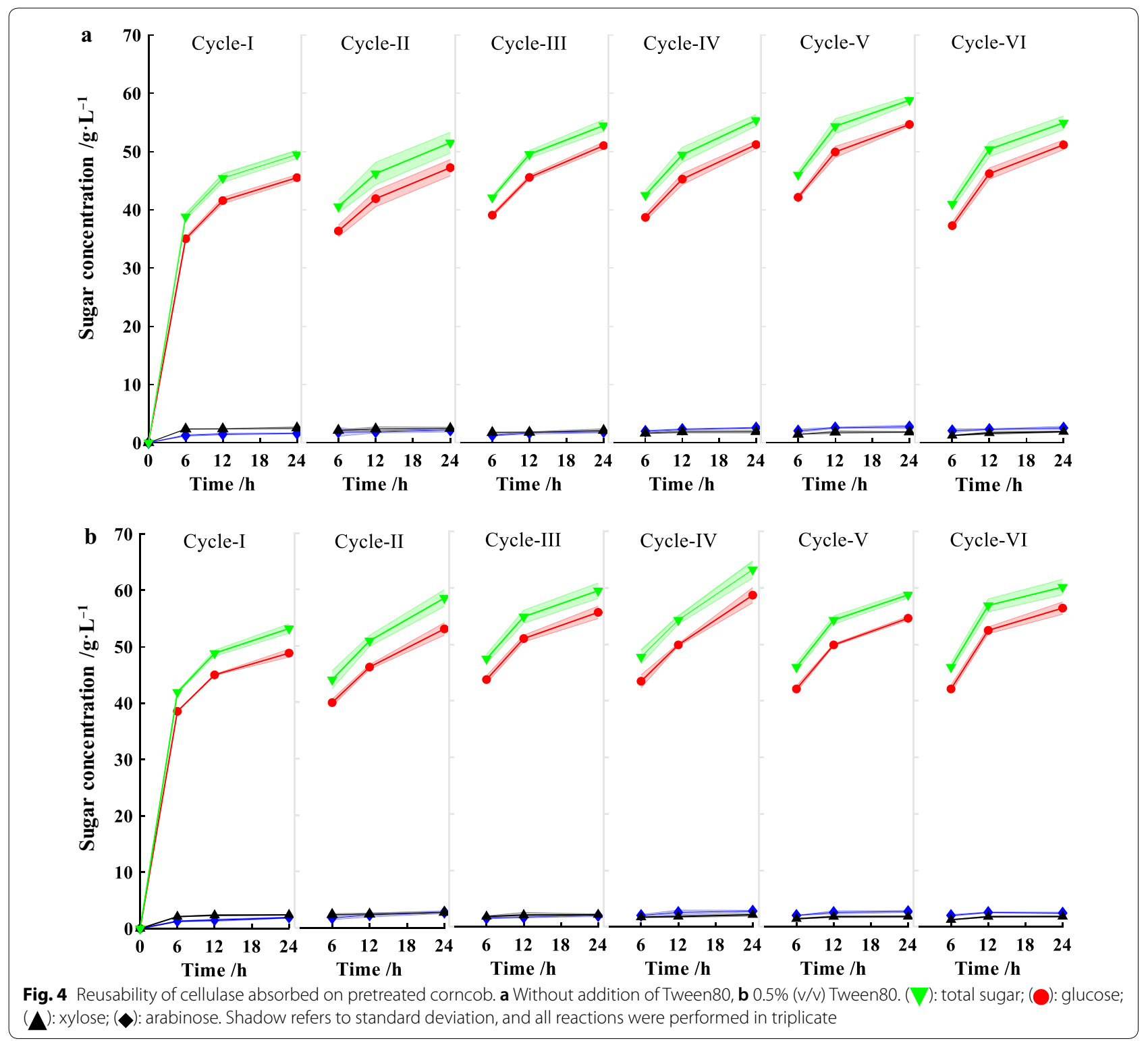

\section{Conclusions}

In this study, several DESs, based on betaine and ethylamine as hydrogen bond acceptors, were newly synthesized and evaluated in the pretreatment of various lignocellulosic biomass. EaCl:LAC with lactic acid as hydrogen bond donor was the most efficient for reducing the recalcitrance of lignocellulosic biomass. Only employing single pretreatment with EaCl:LAC, both high hemicellulose and lignin removal were achieved. Facile pretreatment process was established with recycled cellulase. The hydrolysate of pretreated corncob was biocompatible and could be directly utilized by $C$. saccharobutylicum for biobutanol fermentation with similar butanol titer and yield as glucose counterpart.

\section{Methods}

Biomass, chemicals and strains

All lignocellulosic biomass used in this study was sourced from a farm in Jinan, Shandong province, China. The biomass was milled by grinder and passed through a $380-\mu \mathrm{m}$ sieve, and dried at $60^{\circ} \mathrm{C}$ for $24 \mathrm{~h}$ before use.

Ethylamine chloride $(\mathrm{EaCl})$ was purchased from Macklin Biochemical Co., Ltd. Cellulase was a generous gift from Vland Biotech Co Ltd. All other chemicals were of analytical grade and purchased from Sinopharm Chemical Reagent Co., Ltd.

Clostridium saccharobutylicum DSM 13864 was purchased from DSMZ. In order to induce sporulation, it was cultivated in Reinforced Clostridia Medium (RCM) 

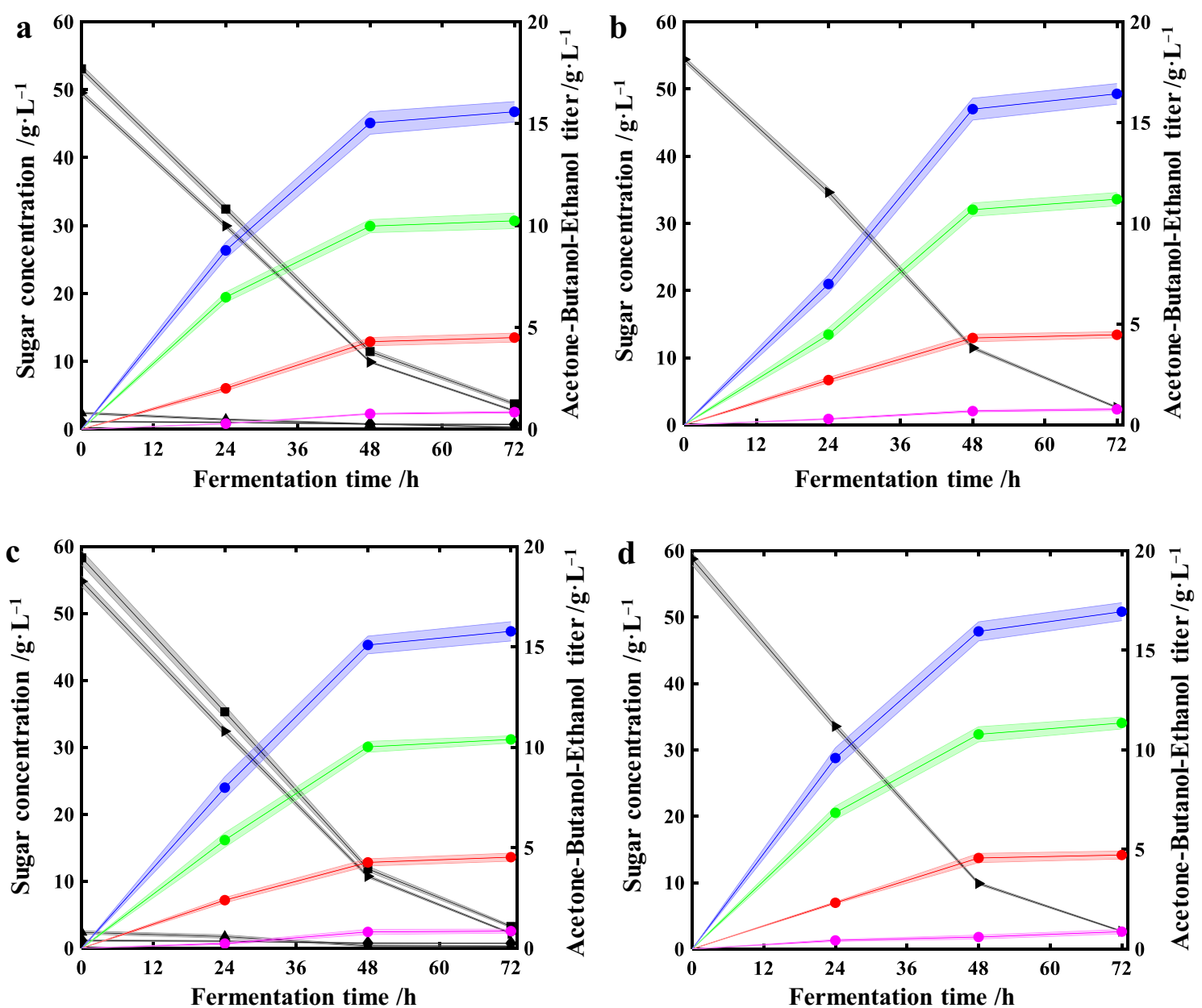

Fig. 5 Biobutanol production from hydrolysates of corncob and glucose as carbon sources. a Hydrolysate of Cycle Vl, b control I (54 g L ${ }^{-1} \mathrm{glucose}$ ),

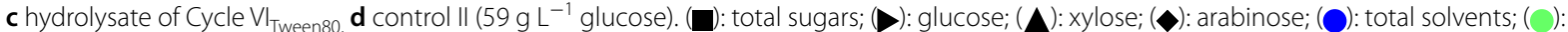
butanol; (O): ethanol; (@): acetone. Shadow refers to standard deviation, and all fermentations were performed in triplicate

Table 3 Biobutanol fermentation with corncob hydrolysates by C. saccharobutylicum DSM13864

\begin{tabular}{|c|c|c|c|c|c|c|}
\hline \multirow[t]{2}{*}{ Carbon source } & \multicolumn{3}{|l|}{ Butanol } & \multicolumn{3}{|c|}{ Acetone-butanol-ethanol (ABE) } \\
\hline & Titer $\left(\mathrm{g} \mathrm{L}^{-1}\right)$ & Yield ${ }^{a}\left(g^{-1}\right)$ & Prod. ${ }^{b}\left(\mathrm{~g} \mathrm{~L}^{-1} \mathrm{~h}^{-1}\right)$ & Titer $\left(\mathrm{g} \mathrm{L}^{-1}\right)$ & Yield $^{\mathrm{a}}\left(\mathrm{g} \mathrm{kg}^{-1}\right)$ & $\begin{array}{l}\text { Prod. } \\
\left(g^{-1} h^{-1}\right)\end{array}$ \\
\hline Cycle VI & 10.2 & $206(136)$ & 0.14 & 15.6 & $315(207)$ & 0.21 \\
\hline Control I & 11.2 & 210 & 0.15 & 16.3 & 320 & 0.22 \\
\hline Cycle $\mathrm{VI}_{\text {Tween80 }}$ & 10.4 & $194(137)$ & 0.15 & 15.8 & $295(208)$ & 0.22 \\
\hline Control II ${ }^{d}$ & 11.4 & 206 & 0.16 & 16.9 & 306 & 0.23 \\
\hline
\end{tabular}

${ }^{a}$ Numbers outside the brackets represent specific yields per total sugars or glucose, numbers inside the brackets refer to specific yields per pretreated corncob

b Prod.: productivity

c Control l: $54 \mathrm{~g} \mathrm{~L}^{-1}$ glucose

${ }^{d}$ Control II: $59 \mathrm{~g} \mathrm{~L}^{-1}$ glucose

at $37^{\circ} \mathrm{C}$ for 7 days and stored at room temperature. Spore suspension $(10 \%, \mathrm{v} / \mathrm{v})$ was inoculated in $12 \mathrm{~mL}$ sterilized RCM and transferred to a desiccator evacuated to a vacuum level of $0.065 \mathrm{MPa}$. Afterwards, the culture was cultivated at $37{ }^{\circ} \mathrm{C}$ for $12-18 \mathrm{~h}$ for further used as the seed medium [27]. 


\section{Synthesis of ethylamine chloride-based DES}

$\mathrm{ChCl}, \mathrm{BaCl}$ and $\mathrm{EaCl}$ as hydrogen bond acceptor, and lactic acid, ethyl glycol, glycerol and urea as hydrogen bond donors were mixed at the ratios as listed in Table 1. The mixture was heated and stirred at $180 \mathrm{rpm}$ in a conical flask with plug to reduce volatilization until a homogenous colorless liquid was formed. The DESs were kept in vacuum desiccator with silica gel for further use.

\section{DFT calculations}

The initial structures for these DESs were constructed with ChemDraw software and optimized via DFT calculations using Gaussian 09 suite. Functionals of B3LYP [49], M062X [37], $\omega B 97 X D$ [50] and basis set of $6-311+G^{* * *}$ were selected to optimize the geometrical structures and calculate the free energy differences. Grimme correction was performed for entropy and Head-Gordon correction was performed for enthalpy. The coordinates of the optimized structure of DESs could be found in Additional file 6.

\section{Pretreatment of corncob with EaCl:LAC}

Ten grams of corncob was added into a three-necked flask containing $150 \mathrm{~g}$ of EaCl:LAC, followed by heating up to $150{ }^{\circ} \mathrm{C}$ in an oil bath. Then the mixture was incubated for $0.5 \mathrm{~h}$ with mechanical agitation (200 rpm). Furthermore, cellulose was regenerated by adding appropriate volume of hot deionized water $\left(85^{\circ} \mathrm{C}\right)$. The regenerated cellulose was filtrated with a 380-mesh sieve, and then washed with water and dehydrated to obtain the pretreated corncob, which was stored at $4{ }^{\circ} \mathrm{C}$ for further use.

Effects of temperature, pretreatment time and solid to liquid ratio on the pretreatment of corncob with $\mathrm{EaCl}: \mathrm{LAC}$ were performed as mentioned above, except for varying the incubation temperature of $90,110,130$ and $150{ }^{\circ} \mathrm{C}$, pretreatment time of $0.5,1.0,1.5$ and $2.0 \mathrm{~h}$, solid to liquid ratios of 1:8, 1:10, 1:12 and 1:15. The pretreated corncobs were subjected to hydrolysis with cellulase and the released sugars were determined employing HPLC (Agilent 1100) equipped with an Aminex HPX$87 \mathrm{H}$ column at $60{ }^{\circ} \mathrm{C}$ with $5 \mathrm{mM} \mathrm{H}_{2} \mathrm{SO}_{4}$ as eluent at a

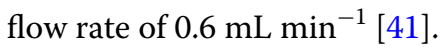

\section{Enzymatic hydrolysis of pretreated corncob}

One gram of the pretreated corncob was added to $12 \mathrm{~mL}$ citrate buffer $(50 \mathrm{mM}, \mathrm{pH} 4.8)$ containing $100 \mu \mathrm{L}$ ampicillin $\left(1 \mathrm{~g} \mathrm{~L}^{-1}\right)$ and $50 \mathrm{FPU}$ cellulase in a 50 -mL flask. The mixture was incubated in a water bath at $50{ }^{\circ} \mathrm{C}$ and $120 \mathrm{rpm}$ for $24 \mathrm{~h}$ for releasing of arabinose, xylose and glucose. Samples $(300 \mu \mathrm{L})$ were withdrawn at $6,12,24 \mathrm{~h}$ and centrifuged at $12,000 \times g$ for $10 \mathrm{~min}$. The resultant supernatants $(100 \mu \mathrm{L})$ were mixed with $900 \mu \mathrm{L}$ ultrapure water. The concentrations of arabinose, xylose and glucose were determined as above described.

Effect of cellulase dosage, hydrolysis time, solid to liquid ratios were investigated. Cellulase was supplemented at dosages of 10, 30, 40, 60 and $70 \mathrm{FPU} \mathrm{g}^{-1}$ pretreated corncob. Different solid to liquid ratios of 1:8, 1:10, 1:12 and 1:15 were adopted. Tween 80 was also added in the hydrolysis mixture at $0.1 \%, 0.5 \%$ and $1.0 \%$. Samples $(100 \mu \mathrm{L})$ were withdrawn from the reaction mixture at 24,48 , and $72 \mathrm{~h}$, and then analyzed as above mentioned.

\section{Recovery of cellulases adsorbed to corncob}

Cycle I of enzymatic hydrolysis was conducted in a 250-mL conical flask, consisted of $5 \mathrm{~g}$ pretreated corncob dispersing in $60 \mathrm{~mL}$ citrate buffer $(50 \mathrm{mM}, \mathrm{pH} 4.8)$ and $50 \mathrm{FPU}$ cellulase. After $24 \mathrm{~h}$, the cellulase adsorbed on residual corncob was collected by filtration and supplemented to the next cycle. Based on previous study, the amount of cellulase added could be reduced by $10 \%$ for each cycle to achieve similar level of total sugars as Cycle I. Samples were prepared and analyzed as above mentioned.

\section{Biobutanol fermentation of C. saccharobutylicum DSM 13864}

The corncob hydrolysates of Cycle $\mathrm{VI}_{\text {Tween80 }}$ and Cycle VI was utilized as carbon source for butanol fermentation by C. saccharobutylicum DSM 13864. Other components of fermentation medium included $10 \mathrm{~g} \mathrm{~L}^{-1}$ of corn steep liquor (CSL), $4 \mathrm{~g} \mathrm{~L}^{-1}$ of $\mathrm{CaCO}_{3}, 2 \mathrm{~g} \mathrm{~L}^{-1}$ of $\left(\mathrm{NH}_{4}\right)_{2} \mathrm{SO}_{4}$, $0.5 \mathrm{~g} \mathrm{~L}^{-1}$ of $\mathrm{K}_{2} \mathrm{HPO}_{4}$ and $0.01 \mathrm{~g} \mathrm{~L}^{-1}$ of $\mathrm{MnSO}_{4} \cdot \mathrm{H}_{2} \mathrm{O}$. Furthermore, the $\mathrm{pH}$ of medium was adjusted to 6.5 with $4.0 \mathrm{M} \mathrm{NaOH}$ and autoclaved at $115{ }^{\circ} \mathrm{C}$ for $20 \mathrm{~min}$. Control experiment was conducted with fermentation medium containing 54 or $59 \mathrm{~g} \mathrm{~L}^{-1}$ of glucose. $10 \%(\mathrm{v} / \mathrm{v})$ of actively growing cell culture was inoculated into sterilized fermentation medium, and anaerobically incubated at $37{ }^{\circ} \mathrm{C}$ in a desiccator $(0.065 \mathrm{MPa})$ [4]. Samples were withdrawn at different time intervals and the contents of acetone, butanol and ethanol (ABE) were analyzed by GC according to previously described methods [27]. All fermentation experiments were carried out in triplicate.

\section{Component analysis and physical characterization of corncob pretreated by EaCl:LAC Component analysis}

Amount of cellulose, hemicellulose, lignin and ash in raw and pretreated corncobs was determined according to previously reported methods [4]. Removal of 
hemicellulose and lignin was calculated according to the following formulas:

$$
\text { Hemicellulose removal }(\%)=\left(1-\frac{\text { Hemicellulose in pretreated corncob }}{\text { Hemicellulose in untreated corncob }} \times \text { solid yield }\right) \times 100 \% \text {; }
$$

Delignification $(\%)=\left(1-\frac{\text { Lignin in pretreated corncob }}{\text { Lignin in untreated corncob }} \times\right.$ solid yield $) \times 100 \%$.

\section{SEM analysis}

Scanning electron microscopy $(5.0 \mathrm{kV}, 1200 \times$ Hitachi $\mathrm{S}-4800$, Japan) analysis was operated to monitor the surface morphological features of corncob before and after pretreatment.

\section{XRD analysis}

The crystallinity of corncob was measured with X-ray diffractometer (XRD), using a D/max 2500 PC diffractometer with $\mathrm{Cu} / \mathrm{Ka}$ radiation source (Rigaku Corporation, Tokyo, Japan). It was operated at a voltage of $60 \mathrm{kV}$ and a current of $300 \mathrm{Ma}$ with a scanning speed of $0.02^{\circ} / \mathrm{min}$ and the $2 \theta$ range from $5^{\circ}$ to $40^{\circ}$. Crystallinity index (CrI) was calculated as following.

$$
\operatorname{CrI}(\%)=\frac{I_{002}-I_{\mathrm{am}}}{I_{002}} \times 100 \% .
$$

$I_{002}$ and $I_{\mathrm{am}}$ imply the intensities of the peaks at near $21.4^{\circ}$ and $16.0^{\circ}$, respectively.

\section{FTIR analysis}

FTIR was performed to detect the chemical structure of corncob using a Nicolet PROTÉGÉ 460 FTIR Spectrometer (Nicolet, Thermo Scientific, Shanghai, People's Republic of China) [20]. FTIR spectra of the samples was recorded between 2000 and $600 \mathrm{~cm}^{-1}$.

\section{Supplementary information}

Supplementary information accompanies this paper at https://doi. org/10.1186/s13068-020-01806-9.

Additional file 1. Comparison on pretreatment of corncob using different DESs.

Additional file 2. SEM analysis of raw or pretreated corncob.

Additional file 3. XRD data of raw and pretreated corncob.

Additional file 4. FTIR spectra of raw and pretreated corncob.

Additional file 5. Optimization the pretreatment conditions of corncob using $\mathrm{EaCl}: \mathrm{LAC}$.

Additional file 6. Coordinates of the optimized structure of DESs.

\section{Abbreviations}

DES: Deep eutectic solvent; $\mathrm{BaCl}$ : Betaine chloride; EaCl: Ethylamine chloride; ChCl: Choline chloride; LAC: Lactic acid; EG: Ethyl glycol; GLY: Glycerol; UR: Urea; DFT: Density functional theory; Crl: Crystallinity index; BSA: Bovine serum albumin; Cycle I: Hydrolysate of the first batch; Cycle I Iween80: Hydrolysate of the first batch with addition of Tween80; Cycle Vl: Hydrolysate of the sixth batch; Cycle IV $\mathrm{T}_{\text {Tween80: }}$ Hydrolysate of the sixth batch with addition of Tween80; Control I: Control medium with $54 \mathrm{~g} \mathrm{~L}^{-1}$ glucose; Control II: Control medium with $59 \mathrm{~g} \mathrm{~L}^{-1}$ glucose; $\mathrm{ABE}$ : Acetone, butanol and ethanol.

\section{Acknowledgements}

We are grateful to Dr. YC He from Changzhou University for support and discussion in XRD and FTIR analysis. We thank American Journal Experts (AJE) for English language editing.

\section{Authors' contributions}

GX: conceptualization, methodology, data curation, writing —original draft, writing - review and editing. HL: formal analysis, investigation, data curation, writing —original draft. WX: methodology, validation, formal analysis. LG: resources, data curation. JD: writing — review and editing. YN: writingreview and editing, supervision, project administration. All authors read and approved the final manuscript.

\section{Funding}

This work was supported by National Key R\&D Program of China (2018A0901700), National Natural Science Foundation of China (21776112), National First-Class Discipline Program of Light Industry Technology and Engineering (LITE2018-07), Natural Science Foundation of Jiangsu Province (BK20171135), Program of Introducing Talents of Discipline to Universities (111-2-06), and Top-notch Academic Programs Project of Jiangsu Higher Education Institutions for the financial support of this research.

\section{Availability of data and materials}

The datasets generated during this study are included in this published article and its Additional files.

\section{Ethics approval and consent to participate}

Not applicable.

\section{Consent for publication}

Not applicable.

\section{Competing interests}

The authors declare that they have no competing interests.

\section{Author details}

${ }^{1}$ Key Laboratory of Industrial Biotechnology, Ministry of Education, School of Biotechnology, Jiangnan University, Wuxi 214122, Jiangsu, China. ${ }^{2}$ Key Laboratory of Guangxi Biorefinery, Nanning 530003, Guangxi, China.

Received: 22 July 2020 Accepted: 27 September 2020

Published online: 09 October 2020 


\section{References}

1. Li J, Zhang M, Wang D. Enhancing delignification and subsequent enzymatic hydrolysis of corn stover by magnesium oxide-ethanol pretreatment. Bioresour Technol. 2019;279:124-31.

2. Biobutanol DP. An attractive biofuel. Biotechnol J. 2007;2:1525-34.

3. Xing WR, Xu GC, Dong JJ, Han RZ, Ni Y. Novel dihydrogen-bonding deep eutectic solvents: pretreatment of rice straw for butanol fermentation featuring enzyme recycling and high solvent yield. Chem Eng J. 2018:333:712-20.

4. Anwar Z, Gulfraz M, Irshad M. Agro-industrial lignocellulosic biomass a key to unlock the future bio-energy: a brief review. J Rad Red Appl Sci. 2014;7:163-73.

5. Yang HH, Tsai CH, Chao MR, Su YL, Chien SM. Source identification and size distribution of atmospheric polycyclic aromatic hydrocarbons during rice straw burning period. Atmos Environ. 2006;40:1266-74

6. Gadde B, Bonner S, Menke C, Garivait S. Air pollutant emissions from rice straw open field burning in India, Thailand and the Philippines. Environ Pollut. 2009:157:1554-8.

7. Korenaga T, Liu X, Huang Z. The influence of moisture content on polycyclic aromatic hydrocarbons emission during rice straw burning. Chemosphere Glob Change Sci. 2001;3:117-22.

8. Jacobs J, Kreutzer R, Smith D. Rice burning and asthma hospitalization, butte country, California, 1983-1992. Environ Health Perspect. 1997:105:980.

9. Torigoe K, Hasegawa S, Numata O, Yazaki S, Matsunaga M, Boku N. Influence of emission from rice straw burning on bronchial asthma in children. Pediatr Int. 2000:42:143-50.

10. Zhang Z, Xie Y, He X, Li X, Hu J, Ruan Z, Zhao S, Peng N, Liang Y. Comparison of high-titer lactic acid fermentation from $\mathrm{NaOH}$ - and $\mathrm{NH}_{3}-\mathrm{H}_{2} \mathrm{O}_{2}$-pretreated corncob by Bacillus coagulans using simultaneous saccharification and fermentation. Sci Rep. 2016:6:37245.

11. He YC, Jiang CX, Chong GG, Di JH, Wu YF, Wang BQ, Xue XX, Ma CL. Chemical-enzymatic conversion of corncob-derived xylose to furfuralcohol by the tandem catalysis with $\mathrm{SO}_{4}\left(2^{-}\right) / \mathrm{SnO}_{2}$-kaoline and E. coli CCZU-T15 cells in toluene-water media. Bioresour Technol. 2017;245:841-9.

12. Himmel ME, Ding SY, Johnson DK, Adney WS, Nimlos MR, Brady JW, Foust TD. Biomass recalcitrance: engineering plants and enzymes for biofuels production. Science. 2007:315:804-7.

13. Reddy N, Yang Y. Properties and potential applications of natural cellulose fibers from the bark of cotton stalks. Bioresour Technol. 2009:100:3563-9.

14. Chiaramonti D, Prussi M, Ferrero S, Oriani L, Ottonello P, Torre P, Cherchi F. Review of pretreatment processes for lignocellulosic ethanol production, and development of an innovative method. Biomass Bioenergy. 2016:46:25-35.

15. Binod P, Sindhu R, Singhania RR, Vikram S, Devi L, Nagalakshmi S, Kurien $\mathrm{N}$, Sukumaran RK, Pandey A. Bioethanol production from rice straw: an overview. Bioresour Technol. 2010;101:4767-74.

16. Kumari $D$, Singh RR. Pretreatment of lignocellulosic wastes for biofuel production: a critical review. Renew Sustain Energy Rev. 2018;90:877-91.

17. Hsu TC, Guo GL, Chen WH, Hwang WS. Effect of dilute acid pretreatment of rice straw on structural properties and enzymatic hydrolysis. Bioresour Technol. 2010;101:4907-13.

18. Elgharbawy AA, Alam MZ, Moniruzzaman M, Goto M. Ionic liquid pretreatment as emerging approaches for enhanced enzymatic hydrolysis of lignocellulosic biomass. Biochem Eng J. 2016;109:252-67.

19. Moniruzzaman M, Goto M. lonic liquids: future solvents and reagents for pharmaceuticals. J Chem Eng Jpn. 2011;44:370-81.

20. Sharma V, Nargotra P, Bajaj BK. Ultrasound and surfactant assisted ionic liquid pretreatment of sugarcane bagasse for enhancing saccharification using enzymes from an ionic liquid tolerant Aspergillus assiutensis VS34. Bioresour Technol. 2019;285:121319.

21. Sorn V, Chang KL, Phitsuwan P, Ratanakhanokchai K, Dong CD. Effect of microwave-assisted ionic liquid/acidic ionic liquid pretreatment on the morphology, structure, and enhanced delignification of rice straw. Bioresour Technol. 2019;293:121929.

22. Zhang $\mathrm{Q}$ de Oliveira VK, Royer S, Jerome F. Deep eutectic solvents: syntheses, properties and applications. Chem Soc Rev. 2012;41:7108-46.

23. Zhang CW, Xia SQ, Ma PS. Facile pretreatment of lignocellulosic biomass using deep eutectic solvents. Bioresour Technol. 2016;219:1-5.
24. Dai Y, Huan B, Zhang HS, He YC. Effective biotransformation of ethyl 4-chloro-3-oxobutanoate into ethyl (S)-4-chloro-3-hydroxybutanoate by recombinant E. coli CCZU-T15 whole cells in [ChCl][Gly]-water media. Appl Biochem Biotechnol. 2017;181:1347-59.

25. Abbott AP, Boothby D, Capper G, Davies DL, Rasheed RK. Deep eutectic solvents formed between choline chloride and carboxylic acids: versatile alternatives to ionic liquids. J Am Chem Soc. 2004;126:9142-7.

26. Gunny AAN, Arbain D, Nashef EM, Jamol P. Applicability evaluation of deep eutectic solvents-cellulase systems for lignocellulose hydrolysis. Bioresour Technol. 2015;181:297-32.

27. Xu GC, Ding JC, Han RZ, Dong JJ, Ni Y. Enhancing cellulose accessibility of corn stover by deep eutectic solvent pretreatment for butanol fermentation. Bioresour Technol. 2016;203:364-9.

28. Lynam JG, Kumar N, Wong MJ. Deep eutectic solvents' ability to solubilize lignin, cellulose, and hemicellulose, thermal stability, and density. Bioresour Technol. 2019;238:684-9.

29. Dai Y, Zhang HS, Huang B, He YC. Enhancing the enzymatic saccharification of bamboo shoot shell by sequential biological pretreatment with Galactomyces sp. CCZU11-1 and deep eutectic solvent extraction. Bioprocess Biosyst Eng. 2017:40:1427-36.

30. Zhang QG, Hu JJ, Lee DJ. Pretreatment of biomass using ionic liquids: research updates. Renew Energy. 2017;111:77-84.

31. Hou XD, Li N, Zong MH. Facile and simple pretreatment of sugar cane bagasse without size reduction using renewable ionic liquids-water mixtures. ACS Sustain Chem Eng. 2013;1:519-26.

32. Smith EL, Abbott AP, Ryder KS. Deep eutectic solvents (DESs) and their applications. Chem Rev. 2014;114:11060-82.

33. Chermette $\mathrm{H}$. Chemical reactivity indexes in density functional theory. J Comput Chem. 1999;20:129-54.

34. Cohen AJ, Mori-Sanchez P, Yang WT. Challenges for density functional theory. Chem Rev. 2012:112:289-32020.

35. Zhang C, Jia $Y Z$, Jing $Y$, Wang HY, Hong K. Main chemical species and molecular structure of deep eutectic solvent studied by experiments with DFT calculation: a case of choline chloride and magnesium chloride hexahydrate. J Mol Model. 2014;20:2374.

36. Chen ZF, McLean B, Ludwig M, Stefanovic R, Warr GG, Webber GB, Page AJ, Atkin R. Nanostructure of deep eutectic solvents at graphite electrode interfaces as a function of potential. J Phys Chem C. 2016;120:2225-33.

37. Zhao Y, Truhlar DG. The M06 suite of density functionals for main group thermochemistry, thermochemical kinetics, noncovalent interactions, excited states, and transition elements: two new functionals and systematic testing of four M06-class functionals and 12 other functionals. Theor Chem Acc. 2008;120:215-41.

38. Atilhan M, Altamash T, Aparicio S. Quantum chemistry insight into the interactions between deep eutectic solvents and $\mathrm{SO}_{2}$. Molecules. 2019;24:2963.

39. Kumar AK, Shah E, Patel A, Sharma S, Dixit G. Physico-chemical characterization and evaluation of neat and aqueous mixtures of choline chloride+lactic acid for lignocellulosic biomass fractionation, enzymatic hydrolysis and fermentation. J Mol Liq. 2018;271:540-9.

40. Tan YT, Ngoh GC, Chua ASM. Effect of functional groups in acid constituent of deep eutectic solvent for extraction of reactive lignin. Bioresour Technol. 2019;281:359-66.

41. Ding JC, Xu GC, Han RZ, Ni Y. Biobutanol production from corn stover hydrolysate pretreated with recycled ionic liquid by Clostridium saccharobutylicum DSM 13864. Bioresour Technol. 2016;199:228-34.

42. Liang Y, Duan WJ, An XX, Qiao YY, Tian YY, Zhou HF. Novel betaine-amine acid based natural deep eutectic solvents for enhancing the enzymatic hydrolysis of corncob. Bioresour Technol. 2020;310:123389.

43. Pandiyan K, Tiwari R, Rana S, Arora A, Singh S, Saxena AK, Nain L. Comparative efficiency of different pretreatment methods on enzymatic digestibility of Parthenium sp. World J Microbiol Biotechnol. 2014;30:55-64.

44. You T, Li X, Wang R, Zhang X, Xu F. Effects of synergistic fungal pretreatment on structure and thermal properties of lignin from corncob. Bioresour Technol. 2019;272:123-9.

45. Ma L, Ma Q, Guo G, Du L, Zhang Y, Cui Y, Xiao D. Optimization of sodium percarbonate pretreatment for improving 2,3-butanediol production from corncob. Prep Biochem Biotechnol. 2018:48:218-25. 
46. Yang B, Wyman CE. BSA treatment to enhance enzymatic hydrolysis of cellulose in lignin containing substrates. Biotechnol Bioeng. 2006;94:611-7.

47. Yang M, Zhang A, Liu B, Li W, Xing J. Improvement of cellulose conversion caused by the protection of Tween-80 on the adsorbed cellulase. Biochem Eng J. 2011;56:125-9.

48. Gao K, Rehmann L. ABE fermentation from enzymatic hydrolysate of $\mathrm{NaOH}$-pretreated corncobs. Biomass Bioenergy. 2014;66:110-5.

49. Becke AD. Density-functional exchange-energy approximation with correct asymptotic behaviour. Phys Rev A. 1988;38:3098-100.
50. Chai JD, Head-Gordon M. Systematic optimization of long-range corrected hybrid density functionals. J Chem Phys. 2008;128:084106.

\section{Publisher's Note}

Springer Nature remains neutral with regard to jurisdictional claims in published maps and institutional affiliations.
Ready to submit your research? Choose BMC and benefit from:

- fast, convenient online submission

- thorough peer review by experienced researchers in your field

- rapid publication on acceptance

- support for research data, including large and complex data types

- gold Open Access which fosters wider collaboration and increased citations

- maximum visibility for your research: over $100 \mathrm{M}$ website views per year

At BMC, research is always in progress.

Learn more biomedcentral.com/submissions 